Volume 8, No.5, September - October 2019

International Journal of Advanced Trends in Computer Science and Engineering

Available Online at http://www.warse.org/IJATCSE/static/pdf/file/ijatcse84852019.pdf

https://doi.org/10.30534/ijatcse/2019/84852019

\title{
Network Traffic Drop Minimization During Maintenance Using Jaya Optimization Algorithm
}

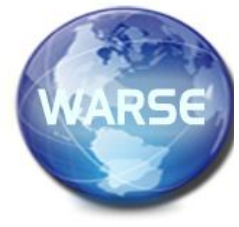

\author{
Ghassan A. Qattan ${ }^{1}$, Amin Salih Mohammed ${ }^{2}$, Moayad Y. Potrus ${ }^{3}$ \\ ${ }^{1}$ PG Student, Dept of Software and Informatics Engineering, Salahaddin University, KR-Iraq. \\ ${ }^{2}$ Assistant Professor, Dept of Computer Engineering, Lebanese French University, KR-Iraq. \\ ${ }^{2}$ Assistant Professor, Dept of Software and Informatics Engineering, Salahaddin University, KR-Iraq. \\ ${ }^{3}$ Assistant Professor, Dept of Software and Informatics Engineering, Salahaddin University, KR-Iraq
}

\begin{abstract}
Network Availability and Quality are important factors which determine a successful telecommunication business nowadays. The Availability of the service is determined by the number of traffic drop or packet drops on the network. It is very important to have minimized these kinds of drops to increase the Availability and the Reliability of any system. External and Internal conditions factors will affect the regular operation and efficiency of any electronic components. Using network telecommunication LAN from Iraq map, and examining the Availability of this network under maintenance, to keep these rates high, the components must be under scheduled maintenance periodically. Planning these maintenance activities must be done carefully to make sure the packet drop and also the maintenance cost will reach to minimum limits, this will be done by finding minimum packet drop when having an accepted fixed cost, and vice Versa. This problem is formulated as the objective function, which is optimized using Jaya Metaheuristic algorithm. The results of this research are trying to find the best time, minimum packet loss, and minimum cost that seems reasonable for the user and reaches to the best maintenance schedule for all components, in the end, reducing the effect of these cut off on network operation.
\end{abstract}

Key words: Network Traffic; Packet drop; Maintenance cost; Preventive Maintenance; Jaya Algorithm

\section{INTRODUCTION}

Since ancient times, human being tries to discover, build and develop everything around him and put everything under his service. One of the most important things that man sought and still seeks, especially after the industrial revolution, namely technology and information. Any work done by the man in terms of discoveries or inventions would have been possible lost if he did not try to keep his permanence or at least maintain it from any external influence, directly or indirectly.

In order for any work to remain under service two important points must be considered, firstly how to develop any work or invention or building and in line with the rapid development of all events and material things, second of the important things for the survival of any work or construction or even a method or theory we must conduct maintenance for this work [11].
The scientists and inventors have reached the period of time when the discoveries or inventions of the new things are relatively few compared to existing ones, which are still dependent on or trying to develop them, especially when building a relatively large project it would be logical not to leave and build another project, but we will work various forms of periodic maintenance of this project to serve us at what time.

Modifying the product or improving its performance after delivery to the user, is considered an approach towards the maintenance in software engineering, and can include four basic categories in the field of maintenance activities, Adaptive: "taking into account the system and the environment surrounding the product and modify the characteristics", Perfective: "improve the functions of the software or change in line with the requirements of the user", Corrective: "Future errors of the product occur, and sometimes those errors are detected by the user, so the newly identified errors should be diagnosed and repaired", and Preventive: "Easy periodic maintenance of the product so as not to affect the overall system and increase the chances of reliability, so that current problems are resolved to ensure that they do not occur in the future [10].

In many Telecommunication or Network Systems, the quality of the provided service is very crucial for companies. The factors that control the service quality are related to service continuity and traffic stability. To keep these two factors at a higher level, the components of the system require a high periodically maintainability process to keep them functioning as best as possible. However, managing the maintenance of these networks can be a risky task when comes to the quality of service if done in a random and non-planned fashion. Therefore, it is very important to plan the maintenance of the network component to make sure the service quality will not drop dramatically.

This research will create and examine traffic data for LAN, which have been adopted from Iraq telecommunication map. This map will contain (2) nodes (Start, and End Gateway routers) plus (14) nodes (Link Gateway routers) which will be testing through one year (52 weeks), and creating ON-OFF possibilities table for this network, considering the path from Start node to End node will always be exist, and for each possibility the packet drop and the cost will be checking for all nodes. Then finding the optimum results using Jaya algorithm. 
The aim of this research is:

1) To produce a best schedule maintenance components plan for one year, so that this schedule will be accepted by the company and it gives the optimum solutions which it will be balanced between packet lost and maintenance cost. Trying to reach to the best point that can give us optimum solution to our problem, which considering the minimum packet drop and minimum maintenance cost.

2) Being in touch to the networks nodes, and that gave us high monitoring to these devices that used in network communications in real life and have the ability to produce report after each stop conditions that appear to decide which type of these networks nodes will do their jobs correctly and will survive or not. Considering adding small and management extra maintenance time will increase the life cycle time of the components and the system will survive at less more than guarantee time.

3) To examine and check how far when can go with this plan if we increase the number of maintenance nodes over the fixed time.

4) The factors that controls the service quality are related to service continuity and traffic stability. To keep these two factors at higher level, the components of the system require a high maintainability process to keep them functioning as best as possible. However, managing the maintenance of these networks can be a risky task when comes to quality of service if done in a random and non-planned fashion. Therefore, it is very important to plan the maintenance of the network component to make sure the service quality will not drop dramatically.

\section{LITERATURE REVIEW}

The great development that has taken place in various fields over the past years. The increasing demand for technology, industry and manufactured products have become one of the objectives of companies to increase their products, and in order to do that, it must raise the level of product quality by increasing its Availability and Reliability. Although modern products have high levels of efficiency and reliability, and a real guarantee of the products after sale, there is no product under any circumstances can operate continuously without a malfunction or minor failure or difficult to lead to a sudden stop. This, in turn, leads to time and money losses for this product and thus reduces the reliability of the product and its manufacturers. The introduction of the maintenance feature increases the chances of the product staying in operation for as long as possible, as maintenance works on or attempts to return the product to its initial state.

The maintenance strategies were developed by time too. The old-style Corrective Maintenance (CM) "Stop and Repair" method of the maintenance is expired and companies are seeking to an innovative Preventive Maintenance (PM) "Guess and Avoid" approach aimed to anticipate the failure instead of fixing them [3]. There are diverse types of PM strategies, like Risk-Based Preventive Maintenance (RBPM) "High risk component of failure will have high frequently maintenance", Time-Based Preventive Maintenance (TBPM) "The age of working component will lead more maintenance time scheduled action, and prevent wearing component and future failure", and Condition-Based Preventive Maintenance (CBPM) "Physical evidence that may occur of the component will have high primitive maintenance action to prevent failure".

To reach the best system Availability under Maintenance performance, risks, and cost must be considered in the first account. CM can produce high costs of production endure, especially in component downtime. The PM should be applied to the system to reduce the likelihood of the failure, however many frequently PM can produce a high cost, and also consuming time and efforts can be wasted too. Maintenance optimization models and the history of components and failures data analysis will be helpful and guiding the decision making in TBPM [12].

When developing or manufacturing materials, companies are currently trying to establish special standards for the product so that its life cycle time is relatively long, so that it is under certain conditions and standards in line with the manufacturers of these products, and when these products are exposed to environmental conditions are not calculated, the impact on the efficiency of the product Clear to the observer, so that the negative change of the operating environment of the product affects the life cycle time of the product. This leads to the use of CBM by periodically monitoring the status of the product and making the appropriate decision for the maintenance operation [5].

The perspective of determining the optimal maintenance policy, as well as the selection of the appropriate strategy for the consumer marketing product, has changed so that maintenance responsibility is not limited to the maintenance department of the product, but also the responsibility of all management departments at different levels [1]. Start with corrective maintenance in case of malfunction (Repair/Restore), and then switch to preventive and predictive maintenance (Prevent/Retain), down to Autonomous maintenance and designed out maintenance (Corporate/Improve), focusing in independent maintenance especially for each product especially for multi-components and stages system, as in figure 1 .

There are many fields in life so that they put the maintenance and how much it effects on system availability and reliability in their high demanded issues, because of its important to prevent or reduce disaster, accident, risk, or cost. This will perform the continuity of the system operations and the project components, which in turn make sure that everything will stay work probably and be online. And the following researches below that take the optimization of maintenance will be a primary consideration in various fields: 


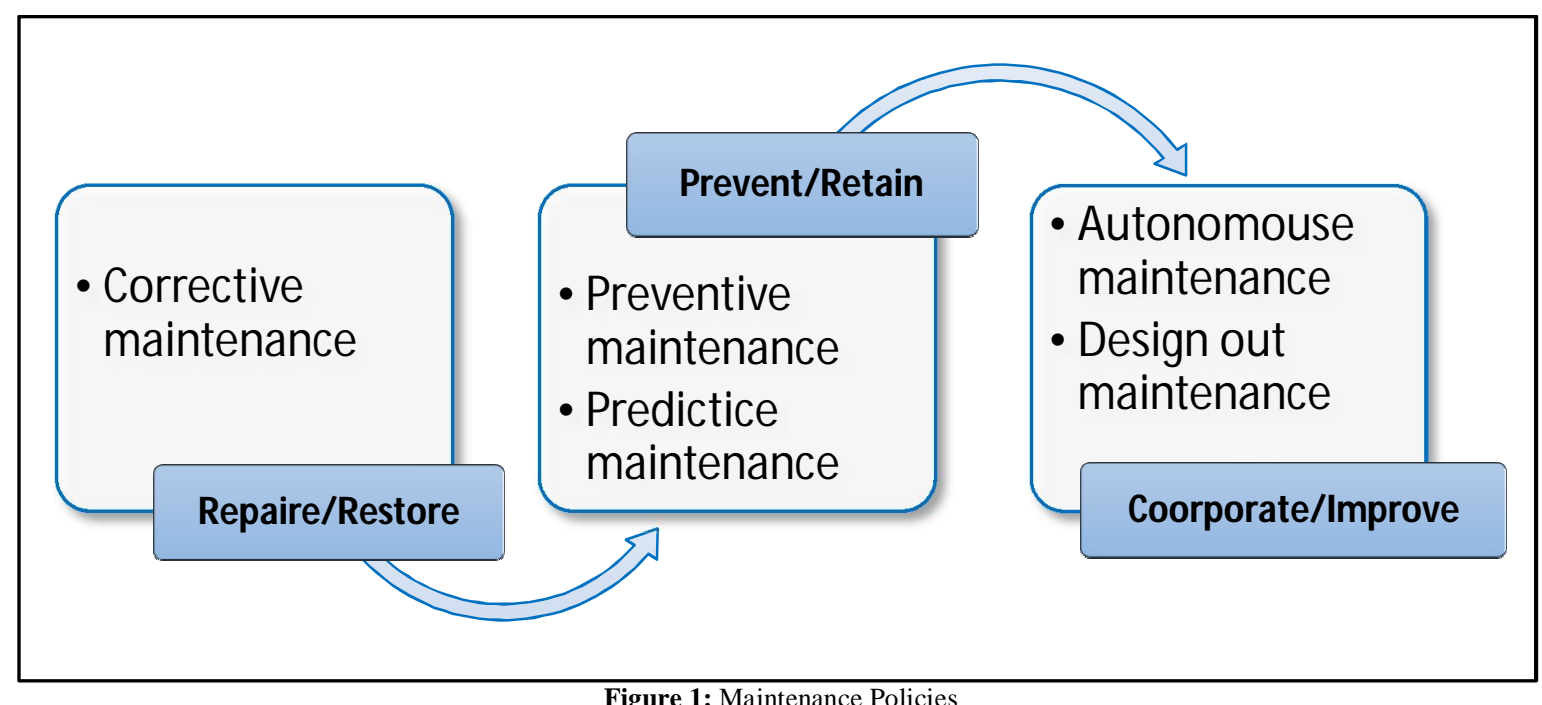

* For Mechanical System field: Maintenance is the backbone of dynamic mechanics, especially for products operating under difficult, volatile and unpredictable conditions. Scheduled preventive maintenance is a major challenge in the offshore wind sector. Many types of research have talked about the maintenance of wind power machines. Satisfactory wind turbine maintenance schedules by combining FUZZY with Genetic Algorithm (GA) to increase reliability and reduce cost [13].

- For Transportation System field: The safety of people when moving from one place to another is a priority for transport companies. To ensure this, periodic maintenance of all transport trains should be carried out so as to ensure the maintenance of trains without affecting the total number of trains under the service of China Railway. ZTN introduces a high-level maintenance system on trains as a 0-1 model, which describes the state of the train under maintenance or not, to control the number of trains under maintenance. By calculating the number of miles traveled, and reading the data taken from the sensors, to reach the best schedule to increase the efficiency of trains in terms of performance and reduce stopping due to accidents or external factors, and to increase the safety of people and goods transported [6].

* For Oil \& Gas Exploration field: This research is submitted to the National Iranian Offshore Drilling Company. When the cost of drilling tools is very high and the surrounding environment is difficult, the demand for preventive maintenance is absolutely essential to increase the reliability of the equipment. The data is obtained from the documentation available in the equipment department and through the use of the GA, which raises the level of failure prediction, cost, and reliability within predetermined time periods [4].

* For Road Network field: The maintenance of road networks is one of the challenges facing many countries, as well as the selection of the appropriate time and optimal choice for the type of maintenance strategy networks so that the cost and time spent maintenance will be the minimum. This research is based on a manual and visual survey of road networks in Indonesia [2], with the help of the updated database and the use of the inevitable deterioration model, all of these lead to determine the priority and type of treatment and its relationship to cost, taking into account the traffic and the climate effects. All this routine work and periodic maintenance and for selecting the periods of maintenance will bring benefits, especially in terms of the cost, the consuming time and the traffic in the future.

\section{MATERIALS AND METHODS}

\subsection{Theory}

The Availability represents the probability that the system is capable of conducting its required function when it is called upon given that it is not failed or undergoing a repair action. Therefore, not only is availability a function of reliability, but it is also a function of maintainability. Table 1 below displays the relationship between reliability, maintainability and availability. The maintainability can be define as how much the components consume less time to do maintenance, and do these components response to maintenance operations fast and easily, so that the system stop situations will be less as possible and this will increase the Availability.

Table 1: Relationship

\begin{tabular}{|c|c|c|c|}
\hline Case & Reliability & Maintainability & Availability \\
\hline 1 & Decrease & Constant Low & Decrease \\
\hline 2 & Constant Low & Decrease & Decrease \\
\hline 3 & Constant High & Increase & Increase \\
\hline 4 & Increase & Constant High & Increase \\
\hline
\end{tabular}

The Availability $(A)$ was written in this Equation 1, which is equal to Mean Time to Failure (MTTF) over Mean Time between Failure $(M T B F)$, which is equal to $(M T T F)$ and Mean 
down Time (MDT). In this paper, maintenance (stop condition) will be consider as another input to the $(A)$ function, the Maintenance Time (MT) will add to (MDT), as shown in Figure 2 , this lead to another formula for the Availability with maintenance $\left(A_{m}\right)$ as shown in Equation 2, and to reach to best case of $\left(A_{m}\right)(M T T F)>>(M D T+M T)$. Increasing $(M T B F)$ value by adding $(M T)$ to will decrease the total $\left(A_{m}\right)$ of any system, but whenever adding small amount of (MT) could be in hours, this will reduce the $(M D T)$ which it is normally come with range between hours to days depending on the situation of each component of the system, and this will increase in $\left(A_{m}\right)$ obviously.

$$
\begin{aligned}
& A=\frac{M T T F}{M T B F}=\frac{M T T F}{M T T F+M D T} \\
& A_{m}=\frac{M T T F}{M T T F+(M D T+M T)}=\frac{M T T F}{M T B F}
\end{aligned}
$$

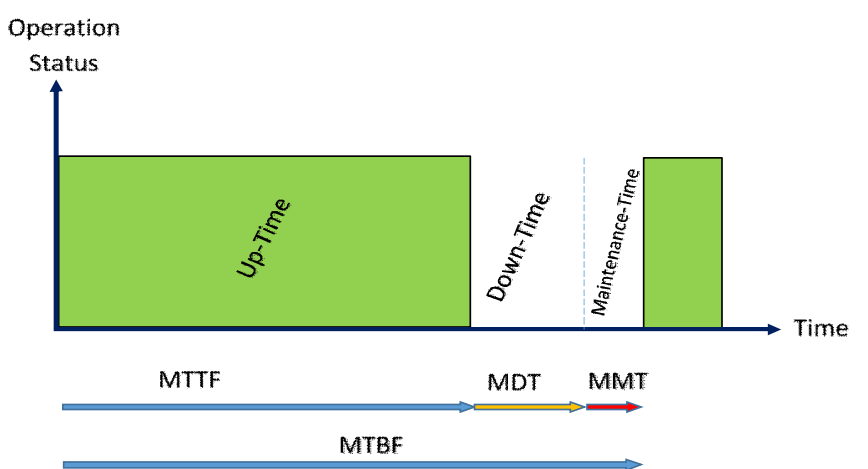

Figure 2: Operation status of system (Availability) over time, showing MTTF, MDT, MMT and MTBF

\subsection{Probability Distributions}

In probability theory and statistics, a probability distribution is a mathematical function that provides the probabilities of occurrence of different possible outcomes in an experiment. In more technical terms, the probability distribution is a description of a random phenomenon in terms of the probabilities of events. Probability distributions have many application in may be used to model the lifetime of components. There are several different types of distributions suitable for different kind of applications. The Weibull distribution is a widely used life distribution in reliability analysis. The distribution is very flexible and can through an appropriate choice of parameters model many types of failure rate behaviors. The Bathtub-curve shown in figure 3 can be modelled easily with three different sets of parameters respectively for the three different phases. The distribution for the useful life period is a special case of the Weibull distribution. This special case of Weibull distribution is equal to an exponential distribution. Hence for the useful life period, the exponential distribution is used. This paper will focus on the third part of bathtub, when increasing in failure rate will be presented, and the Cumulative Distribution Function (CDF), which described by the Equation 3, consider to be as the probability of failure rate over the time consuming.
$C D F=1-e^{\left(\frac{-x}{a}\right)^{b}}$, where $a, b$ represent the scale and shape factors

This research paper focused on the third stage of failure rate (Increasing Failure Rate), assuming the system pass the previous stages, and all components going toward wear out direction.

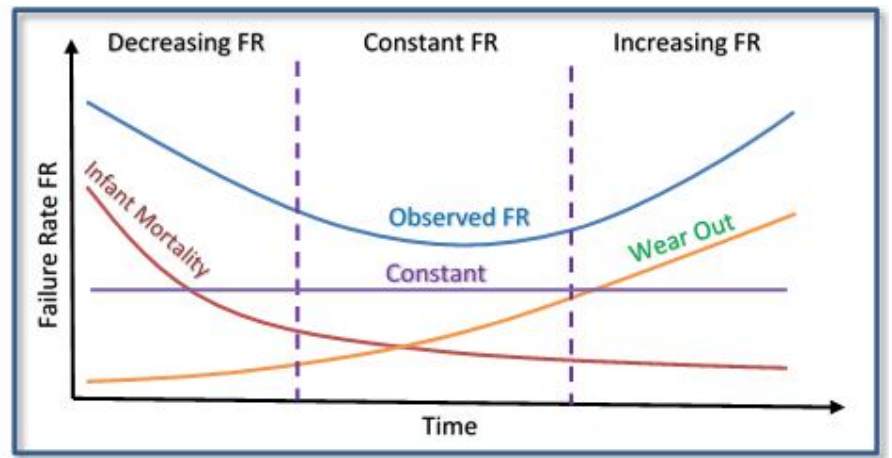

Figure 3: Failure rate represented by Bathtub-curve, showing the three part of life cycle of component

\subsection{JAYA Algorithm}

There are many optimization algorithms which can be classified in many ways, depending on the focus and characteristics. Evolutionary Algorithms, like Genetic Algorithm (GA), 1970, Swarm Intelligence like Particle Swarm Optimization (PSO), 1995, Natural Phenomena, like Gravitational Search Algorithm (GSA), 2009. All these algorithms have their common controlling parameters like population size, number of generations, and their own algorithm-specific control parameters.

The Jaya algorithm , which it firstly announced in 2016 is a modern Metaheuristic optimization algorithm [8], it can be define as "A simple optimization algorithm for solving constrained and unconstrained optimization problems". It classified under Teaching Learning Based Optimization (TLBO) algorithm [9], which does not require any algorithm specific parameters, only common controlling parameters for its working, it focus to move one step toward the best solution and one step against the worst solution in each iteration, so that the overall process time of optimization problem will decreasing significantly.

Trying to select the best optimization algorithm to give the best solution is confusing situation [7] mentioned and compared four important optimization algorithm Pattern Search (PS), Simulated Annealing (SA), Genetic Algorithm (GA), and Jaya Algorithm (JAYA), by practicing these algorithms using standard benchmark functions. These comparing concluded that most of these algorithms yielded somewhat fluctuating results from the target, but due to the characteristics of the (JAYA) algorithm, it proved highly effective and efficient in giving the best solutions when applied to these benchmark functions. 


\subsection{Creating Network Model and Gathering Data}

\subsubsection{Packet Drop Data}

This section will use part of real map of Iraq network connection, which is created by the QualityNET Company, as shown in Figure 4(a,b), which will be the case study in this paper.

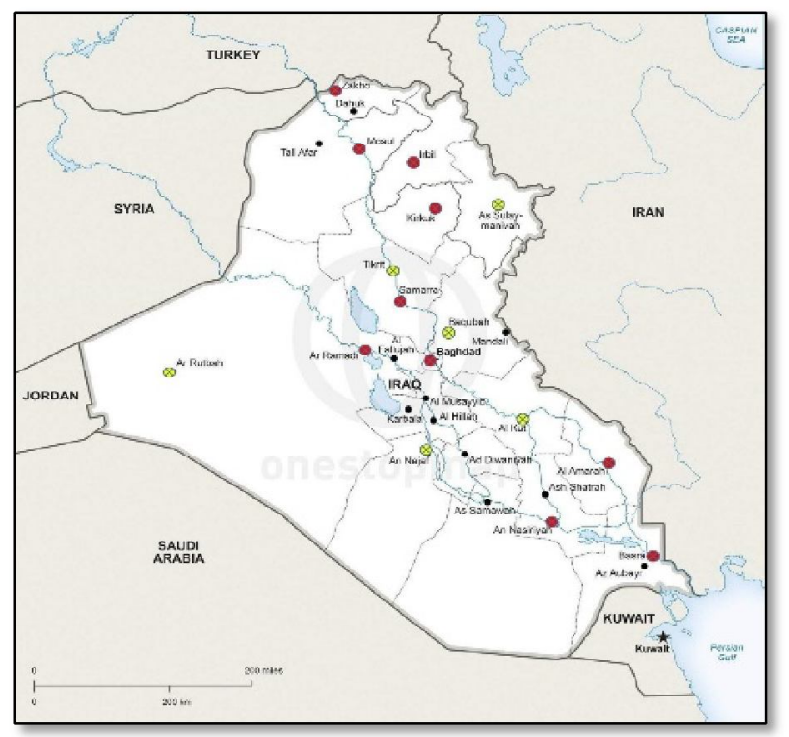

Figure 4a: Iraq with Important States

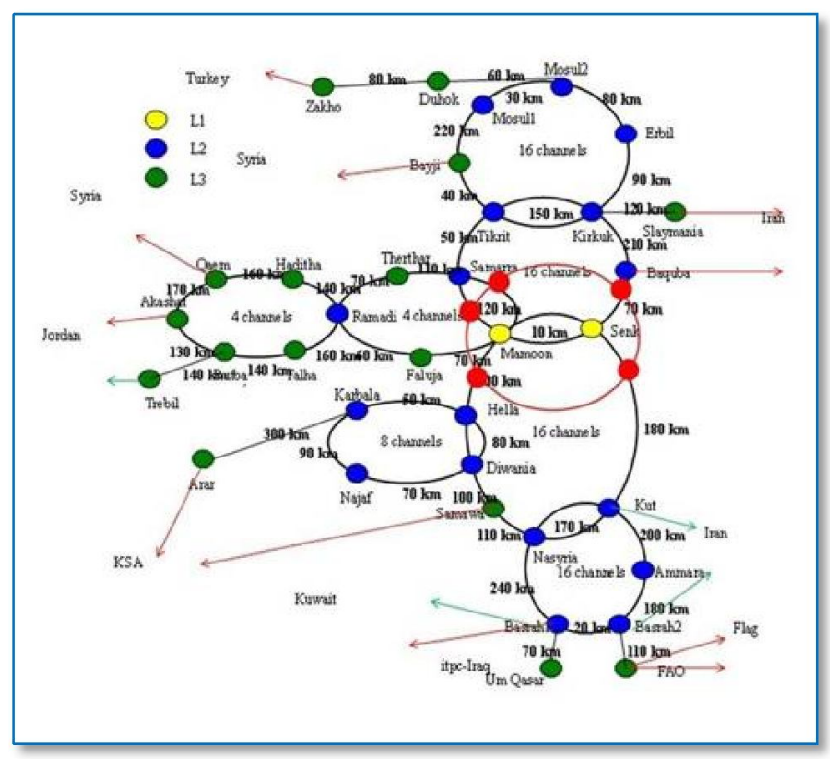

Figure 4b: Internet connection of Iraq states created by QualityNET

Then using the network simulator OPNET, and from part of the Figure 4(b) to create different scenarios and get the results of each one, the overall network that will be as the main model of this paper, which are show the adapted network form shown in Figure 5(a), the OPNET model shown in Figure 5(b), and the inside of each node of the model as shown in Figure 5(c), there are different type of network topology, wire and wireless, and many servers, all that will guarantee traffic data, which is important to get the results for each node.

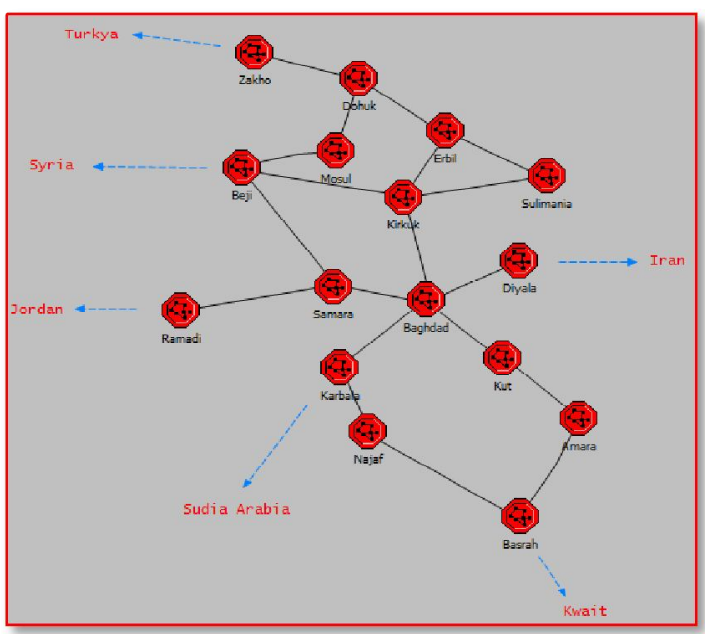

Figure 5a: real states connection

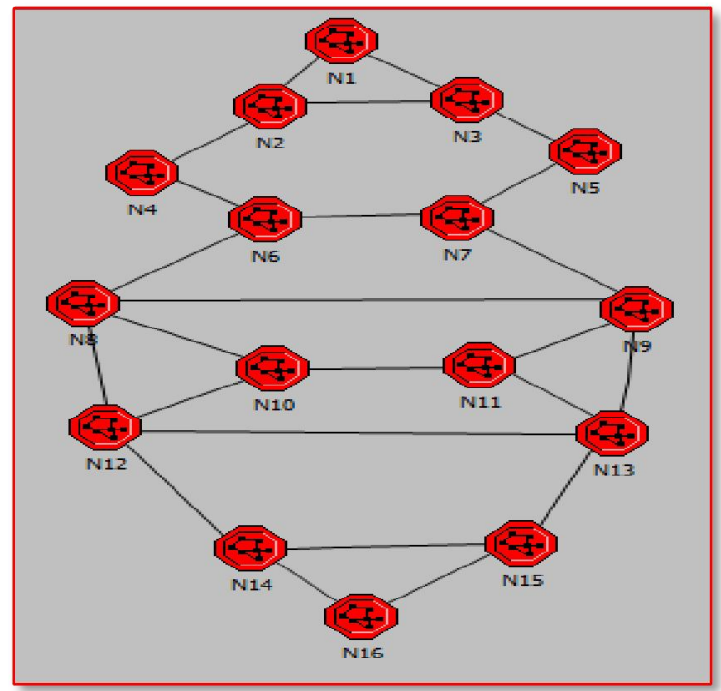

Figure 5b: The Network model on OPNET

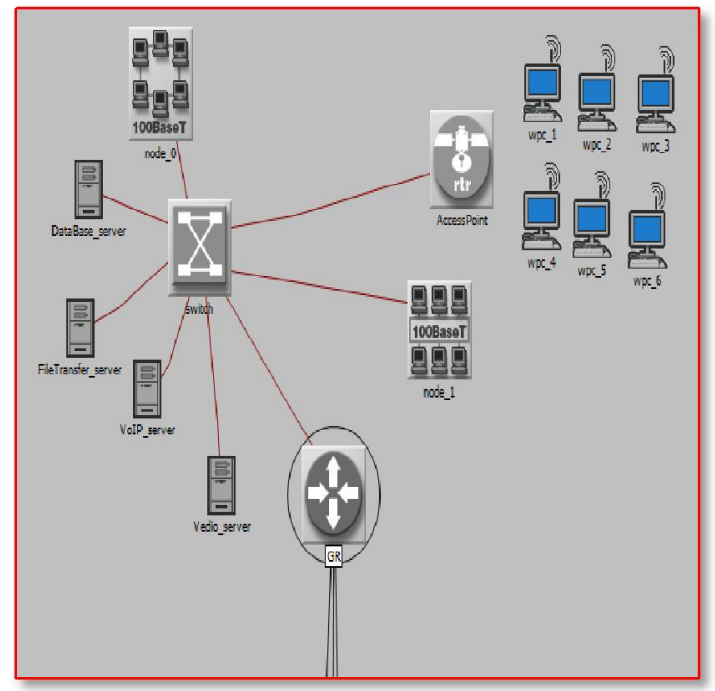

Figure 5c: verity of components inside each node 
After connect the model, which will contain 16 nodes, the data will be pass through the nodes from node1 (Source) to the node16 (Destination), the results will be categories due to the conditions of the rest nodes into four main groups that shown in Table 2, and since we have 16 nodes, so the possibility will equal to $\left(2^{16}=65,536\right)$ cases, and following the conditions and important information that mentioned below will reduce number of paths and this will decrease the possibility:

1) $\mathrm{N} 1$, and $\mathrm{N} 16$ will be $\mathrm{ON}$ always (to make sure that data will pass from source N1 to destination N16).

2) Neglecting the nodes in OFF state that make the path from N1 to N16 not exist. (i.e. N2 and N3 must not be OFF in the same time).

3) The number of OFF state will be not exceeded 3 nodes, in this research hopping to increase the network size and the OFF state in the future.

4) From (1-3), the overall possibilities will reduce to 134 accepted possibilities.

5) These possibilities will change due to the size and the topology of network connections.

6) The period of all possibilities will be 1 year.

7) This is one example of each category:

$1000000000000001=$ belong to cat-Group Zero $1000100000000001=$ belong to cat-Group One $1001000000010001=$ belong to cat-Group Two 101000001000 0101= belong to cat-Group Three

Table 2: Categories

\begin{tabular}{|l|l|c|}
\hline \multicolumn{1}{|c|}{ Categories } & \multicolumn{1}{c|}{ Conditions } & Accepted Possibility \\
\hline Group Zero & All nodes were in ON state. & 1 \\
\hline Group One & Only one node is in OFF state. & 14 \\
\hline Group Two & Two nodes were in OFF state. & 71 \\
\hline Group Three & Three nodes are in OFF state. & 48 \\
\hline
\end{tabular}

In the Figure 6, it shows part of the all possibility for three nodes in OFF state, that have been gotten from OPNET, assuming that this network of Figure 5(b), support FTP, routing type OSPF, and the duration was 365 days (52 weeks). The output gives results for these possibilities.

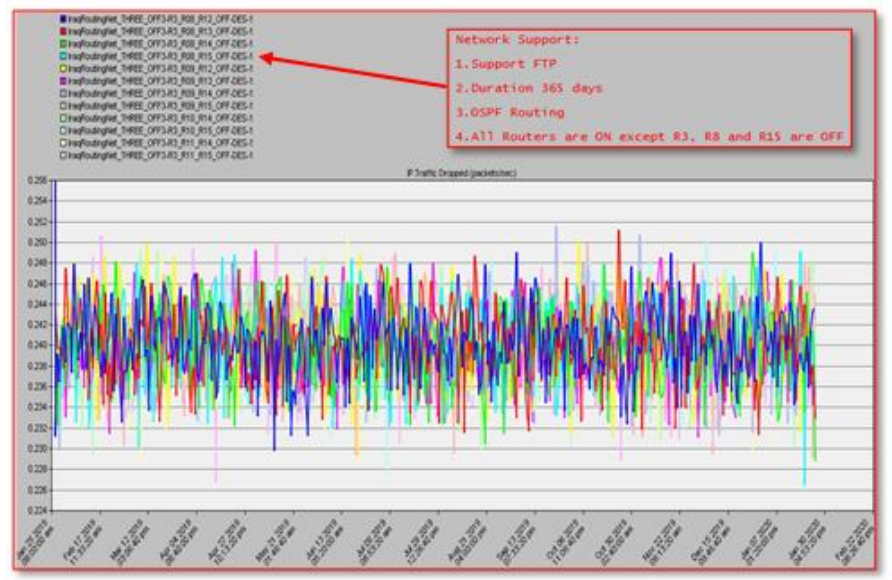

Figure 6: O/P traffic drops of the network when three gateway router were OFF (under maintenance condition)

After finishing all scenarios (accepted possibilities), the results that been gotten will be ordered in array ( 52 weeks by 134 possibilities), which consisting of the packet drop that calculated from the OPNET simulator, each possibilities will return the binary conditions matrix of the 14 routers by 52 weeks. Then applying the last matrix $\mathrm{A}(14,52)$ as input to JAYA algorithm to find the optimum packet drop, and also for the cost in the Analysis Data section.

\subsubsection{Cost Data}

The Total Cost function (TC), which it shown in Equation 4, will be equal to summation of the Failure Cost (FC) and the Maintenance Cost (MC). In general, the amount of (FC) is much more than (MC), however the neglecting or canceling the (MC) will led the component to work imperfectly, and the system will stop gradually at the end.

$$
T C=F C_{(I n d+D e p)}+M C_{(I n d+D e p)}
$$

The (FC), and (MC) will consist of the summation of (Independent, and Dependent) cost, $\left(F C_{\text {Ind }}\right)$ can be defined as the fixed cost or down time due to any failure (cool down, diagnostics, technical and logistics support waiting, disassemble, re-assemble, start-up, and warm up), whereas $\left(F C_{D e p}\right)$ is the cost or time of repair or replacement of the failed component. The (FC) part of the equation 4 related on (CDF) to find the probability failure for each router, and Figure 7 will illustrate the failure rate of randomly 4 gateway routers, noticing that each one will have different deterioration curve depending on many factors like (Quality of product made, Working hours, Climate and surrounding condition ... etc.). The $\left(M C_{\text {Ind }}\right)$ can be defined as the fixed cost or down time due to any maintenance (stop the system, cool down, disassemble, re-assemble, start-up, and warm up), whereas $\left(M C_{D e p}\right)$ is the cost or time of the specific maintenance. The (MC) part related on the condition of router situation $\mathrm{ON}$ or OFF.

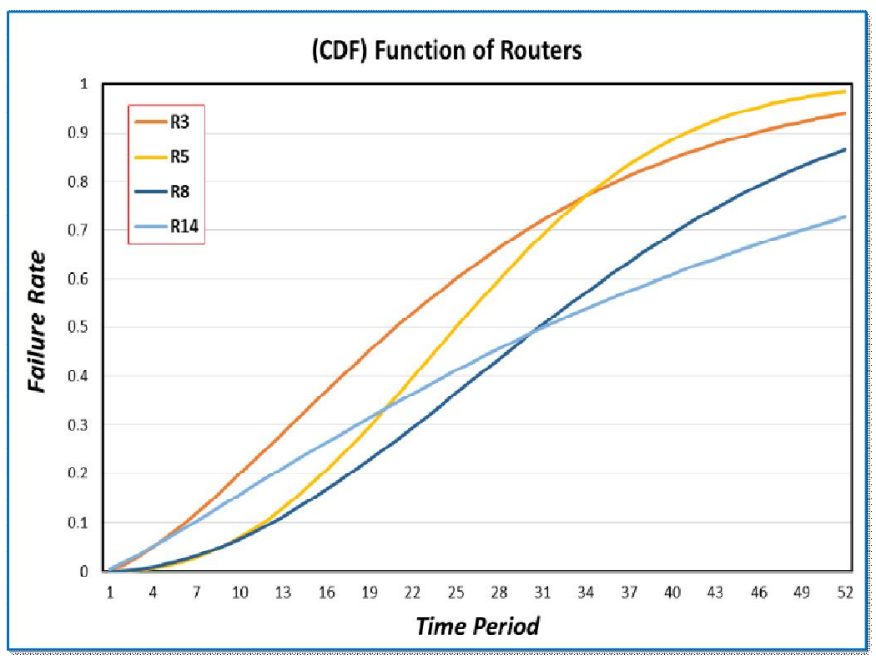

Figure 7: Failure Rate of 4-Random routers (R3, R5, R8, R14)

There are different type of maintenance strategies can be apply to any system's component, these types of strategies will depend on the how long and how much can the system give high rates of Availability and Reliability to the users, considering that (MC) are varied for each strategy, the most known strategies types are:

1) Break down Maintenance (BDM): the maintenance will happened after the component stopped suddenly at any 
time. (i.e. changing the component, when it stopped working), it have no (MC), highest risk to fail, and lowest system Availability, especially when break down happened.

2) Condition Based Maintenance $(\mathrm{CBM})$ : the maintenance will done only if the component reach to a condition or limits of working that maintenance must be apply to it. (i.e. check the working of the component, when it reach below the minimum limits), it have low (MC) but critical Availability because break down could happened before it reach to condition point.

3) Time Based Maintenance (TBM): the maintenance will apply to the component at fixed periodic of time, it do not depend on the component conditions. (i.e. checking the component every week), it have high (MC) and high Availability comparing with (CMB).
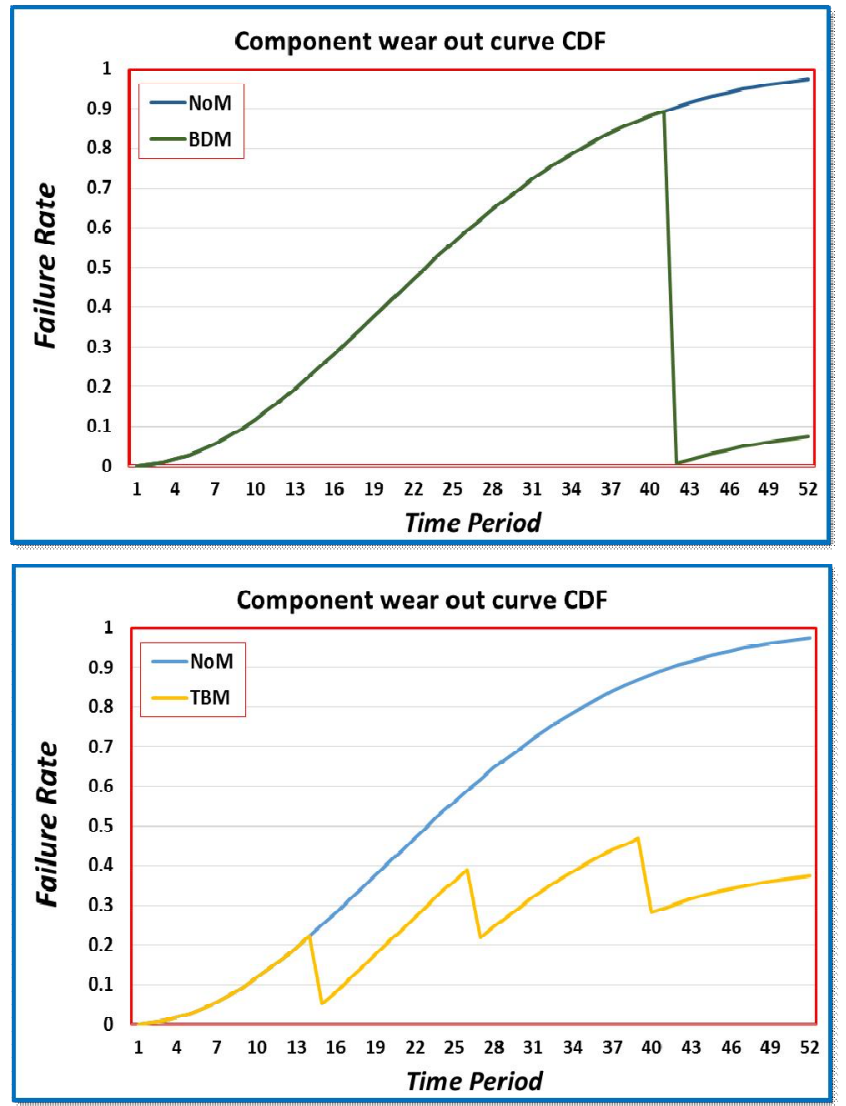

4) Optimum Preventive Maintenance (OPM): the maintenance will apply to the component periodically, and it do not just depend on neither the component conditions nor fixed time, but it functionality of the cost consuming to do maintenance. The (OPM) which is applied in this research will have varied amount of (MC) between the strategies (CBM) and (TBM), putting on account doing many or less maintenance will increase the cost and cause system break down respectably.

Figure 8 will illustrate these types of strategies (BDM), (CBM), (TBM), and (OPM) trying to see how the failure rate will be with and without maintenance operations.
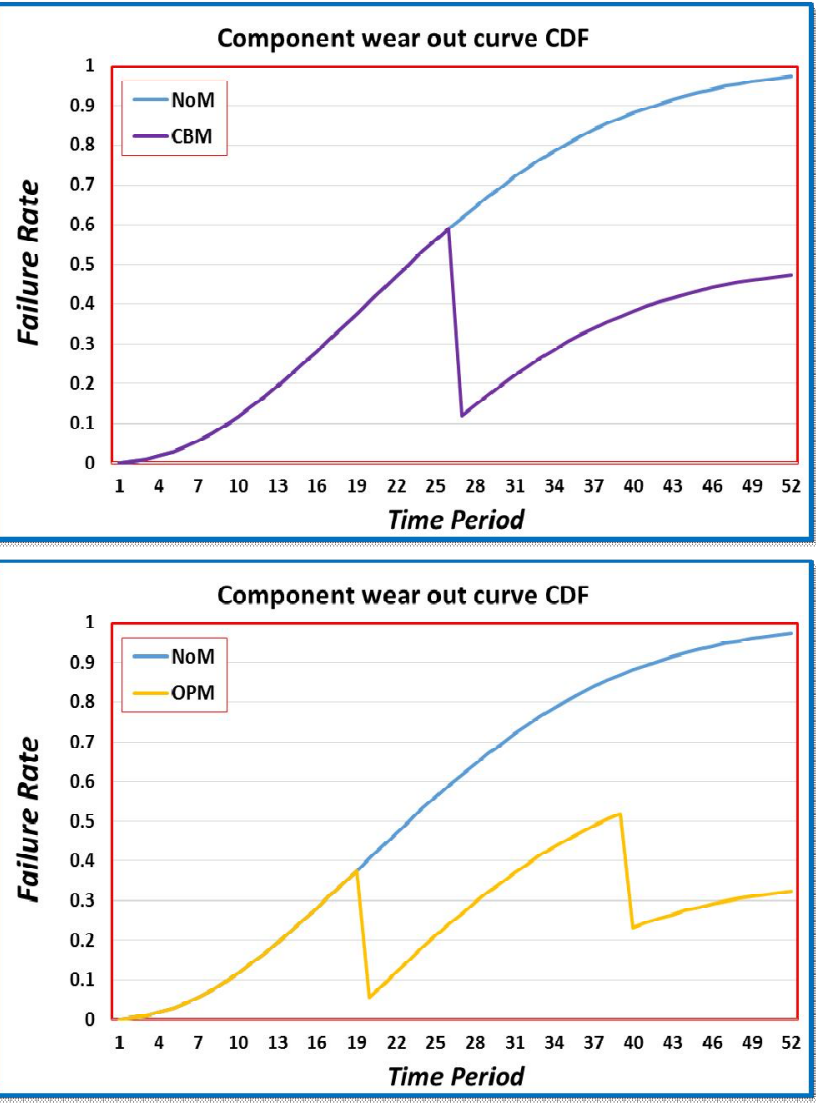

Figure 8: (a) Shows the component wear out in no maintenance (NoM) \& Break Down Maintenance BDM, (b) NoM \& Conditional Based Maintenance CBM, (c) NoM \& Timed Based Maintenance CBM, (d) NoM \& Optimum Preventive Maintenance OPM

Selecting the best strategy is very important and difficult jobs. It depends on many factors, and every system have its complicated working, maintenance, and stopping scenarios. This research paper is concerned with the network packet drop data and the total cost consuming when maintenance happened. Trying to reach to the points that will satisfy the user for both directions. The first scenario is done by fixed packet drop at a low limit, and the cost is not important. The second scenario is done when fixed the cost to a limit, and the packet drop will be less important. And if combining between $1^{\text {st }}$ and $2^{\text {nd }}$ scenarios, the best packet drop and best cost will be found for this system, or any larger or complicated one.
Whatever the system stopped for maintenance operations or not the Table 3 shows the factors that (CDF) depend to produce the Failure Cost, where the Fixed Failure Cost $=23000$, and the Fixed Maintenance Cost $=500$, the last two values can be selected depend on the real cost of your area.

\subsection{Data Analysis and Optimal Solution}

This section will explain how to calculate the minimum packet drop and minimum cost data. The analysis of data that been gotten, will divided into two main fields, where:

- $\quad r=14$ (routers), $w=52$ (weeks)

- $\quad k=$ candidate solutions, $j=J a y$ a loop iterations 
- $\quad(x)$ will be the input binary matrix $A(r, w, k)$

- $\quad A P=$ Accepted Possibilities (134)

- $\quad P D(x)=$ function return packet drop data

- $\quad M C(x)=$ function return maintenance cost data

- fixed_Cost, and fixed_Drop are constant values assigned by the user

- the packet drop can we get when all routers are ON per year $=3184$

- the cost can we get when all routers are ON per year $=29787$

The last two values fixed_Cost, and fixed_Drop will changed each time to reach to best solution Tables 4,5,6 illustrate different values of inputs for 20 executions and their results.

First Scenario: Minimum Packet drop, Fixed Maintenance Cost:

Step 1: Create binary matrix $A(r, w, k)$ from the $A P$

Step2: $\quad$ best $1=\min (P D(A))$, and worst $1=\max (P D(A))$, for all $k$

Step3: JAYA algorithm Loop started, $B_{j}=\operatorname{Modify}\left(A_{j}\right)$

Step4: If $B_{j}$ is not from $A P$, Then round $B_{j}$ to nearest valid AP

Step5: $\quad$ best $2=\min \left(P D\left(B_{j}\right)\right)$, and worst $2=\max \left(P D\left(B_{j}\right)\right)$, for all $k$

Step6: If best $2<$ best1, Then $A_{j}=B_{j}$, best $1=$ best 2 , worst $1=$ worst 2

Step7: Calculate $M C\left(A_{j}\right)$

Step8: If $M C\left(A_{j}\right)>$ fixed_Cost, Then Penalty will added to the total $P D\left(A_{j}\right)$

Step9: Repeat steps 3-to-8 until JAYA loop ended

Table 3: CDF Cost Analysis

\begin{tabular}{|l|c|c|c|c|c|c|c|c|c|c|c|c|c|c|}
\hline \multicolumn{1}{|c|}{ Parameter } & R1 & R2 & R3 & R4 & R5 & R6 & R7 & R8 & R9 & R10 & R11 & R12 & R13 & R14 \\
\hline Failure Cost & 2500 & 2400 & 2700 & 2100 & 2550 & 2300 & 2600 & 2050 & 2350 & 2400 & 2550 & 2150 & 2000 & 2450 \\
\hline Maintenance Cost & 35 & 32 & 52 & 42 & 35 & 32 & 53 & 42 & 35 & 32 & 55 & 42 & 40 & 35 \\
\hline Scale value (a) & 2.2 & 2 & 2.05 & 1.9 & 2.2 & 2 & 2.05 & 1.9 & 2.2 & 2 & 2.05 & 1.9 & 2 & 2.1 \\
\hline Shape value (b) & 2.2 & 2.1 & 2.8 & 2.4 & 2.2 & 2.5 & 2 & 2.4 & 2.2 & 2.5 & 2 & 2.4 & 2.7 & 2.5 \\
\hline Increment value & 0.016 & 0.011 & 0.013 & 0.01 & 0.017 & 0.014 & 0.012 & 0.01 & 0.018 & 0.014 & 0.012 & 0.016 & 0.019 & 0.015 \\
\hline
\end{tabular}

The output of first scenario illustrated in the Table 4, which it show different inputs, output, and executions, where the Figures 9, 10 shows one execution, which it gives the $P D$, and the $M C$ respectably, when the Jaya loop iterations $=100$, the candidate solution $(\mathrm{k})=10$, the $\min (P D)=3728$ at $\mathrm{j}=94$, and the fixed_Cost $=37000$.

Table 4: Output of First Scenario

\begin{tabular}{|c|c|c|c|c|c|c|}
\hline & $\begin{array}{l}\text { JAYA } \\
\text { LOOP }\end{array}$ & $\begin{array}{c}\text { Fixed } \\
\text { Cost }\end{array}$ & $\begin{array}{l}\min \\
\text { Drop }\end{array}$ & $\begin{array}{l}\text { The } \\
\text { Cost }\end{array}$ & $\begin{array}{l}\text { JAYA } \\
\text { Index }\end{array}$ & $\begin{array}{l}\text { Maintenance } \\
\text { times/Year }\end{array}$ \\
\hline 1 & \multirow{4}{*}{100} & 33000 & 276519 & 35727 & 89 & 109 \\
\hline 2 & & 35000 & 3868 & 34696 & 90 & 98 \\
\hline 3 & & 37000 & 3728 & 35505 & 94 & 95 \\
\hline 4 & & 39000 & 3596 & 36514 & 91 & 74 \\
\hline 5 & \multirow{4}{*}{200} & 33000 & 116928 & 34131 & 194 & 89 \\
\hline 6 & & 35000 & 3776 & 34227 & 187 & 63 \\
\hline 7 & & 37000 & 3704 & 35621 & 194 & 65 \\
\hline 8 & & 39000 & 3572 & 38107 & 151 & 77 \\
\hline 9 & \multirow{4}{*}{400} & 33000 & 91948 & 33881 & 380 & 83 \\
\hline 10 & & 35000 & 3633 & 34627 & 399 & 67 \\
\hline 11 & & 37000 & 3581 & 36669 & 248 & 107 \\
\hline 12 & & 39000 & 3503 & 36914 & 385 & 75 \\
\hline 13 & \multirow{4}{*}{800} & 33000 & 61019 & 33573 & 679 & 81 \\
\hline 14 & & 35000 & 3599 & 34820 & 754 & 90 \\
\hline 15 & & 37000 & 3488 & 36547 & 603 & 68 \\
\hline 16 & & 39000 & 3465 & 37720 & 602 & 75 \\
\hline 17 & \multirow{4}{*}{1600} & 33000 & 3715 & 32808 & 1174 & 84 \\
\hline 18 & & 35000 & 3494 & 33857 & 1330 & 81 \\
\hline 19 & & 37000 & 3476 & 36833 & 1293 & 70 \\
\hline 20 & & 39000 & 3409 & 35585 & 1237 & 46 \\
\hline
\end{tabular}

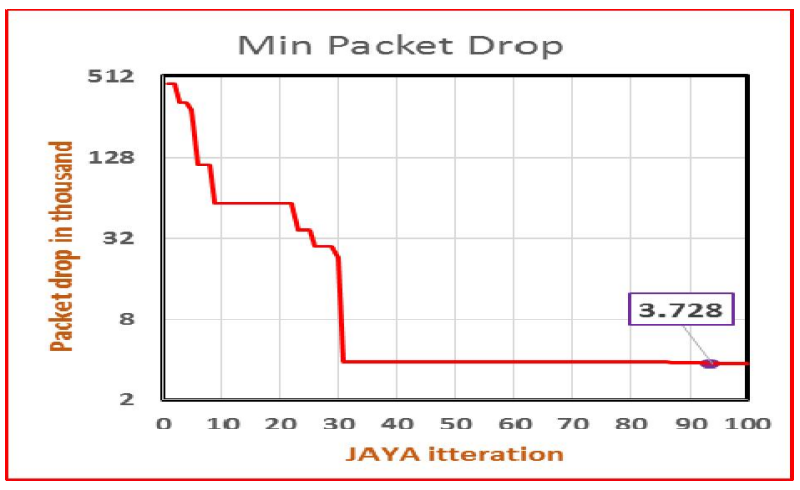

Figure 9: MC decresing with JAYA itteration

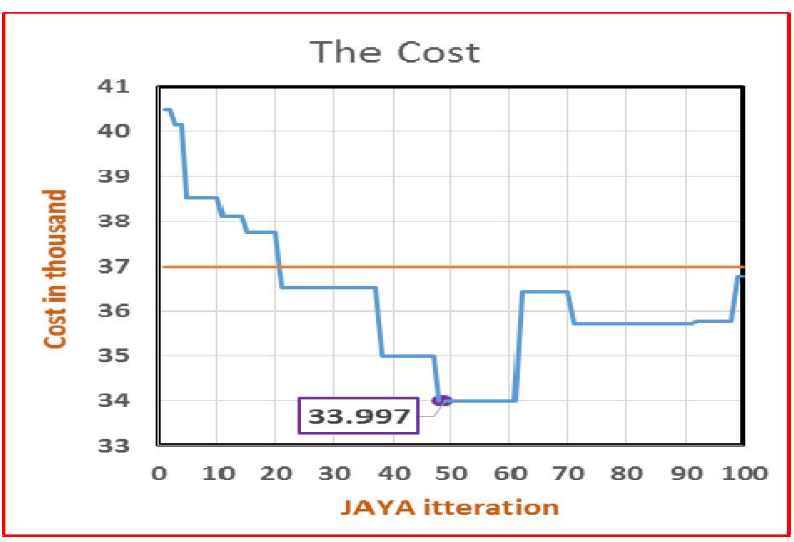

Figure 10: MC variation with JAYA itteration at fixed_Cost $=37000$ 
Table 5 shows specific values "derived from Table 4" of the $P D$, and how it decrease gradually, while the $M C$ were varied for each Jaya iteration. Figure 11 shows the effect of Jaya loop number on calculating the $P D$, and how the $P D$ improved while the Jaya loop were increase from (100-1600) loop iterations, when using different values of fixed_Cost (3300039000).

Table 5: PD Values

\begin{tabular}{|c|c|c|c|c|c|}
\hline fixed_Cost & JAYA $=100$ & 200 & 400 & 800 & 1600 \\
\hline 33000 & 276519 & 116928 & 91948 & 61019 & 3715 \\
\hline 35000 & 3868 & 3776 & 3633 & 3599 & 3594 \\
\hline 37000 & 3723 & 3704 & 3581 & 3488 & 3476 \\
\hline 39000 & 3596 & 3572 & 3503 & 3465 & 3409 \\
\hline
\end{tabular}

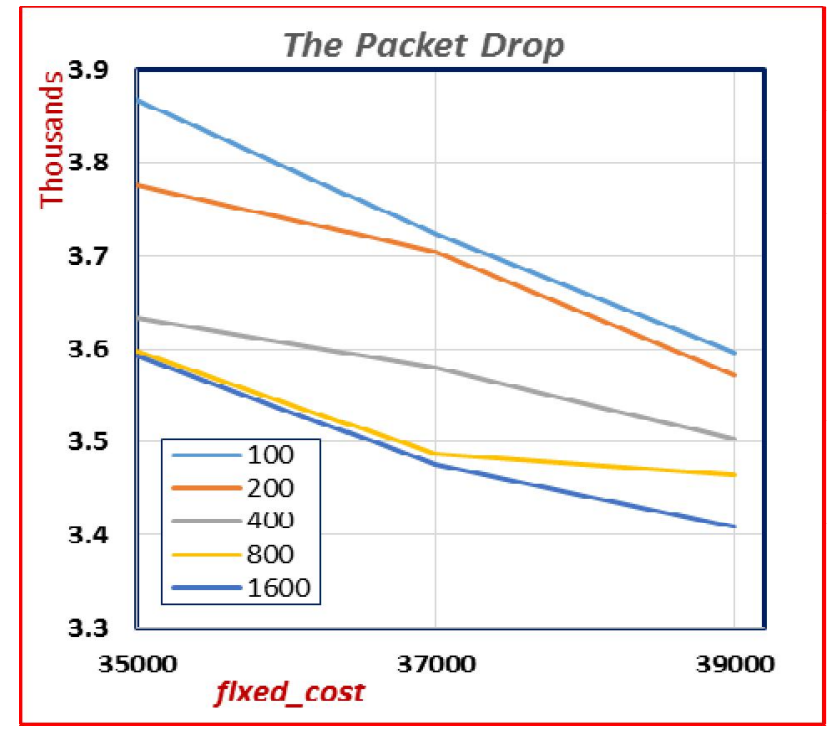

Figure 11: Effect of JAYA Loop

Second Scenario: Minimum Maintenance Cost, Fixed Packet drop:

Step1: Create binary matrix $\mathrm{C}(\mathrm{r}, \mathrm{w}, \mathrm{k})$ from the AP

Step2: $\quad$ best $1=\min (M C(C))$, and worst $1=\max (M C(C))$, for all $\mathrm{k}$

Step3: JAYA algorithm Loop started, $D_{j}=\operatorname{Modify}\left(C_{j}\right)$

Step4: If $D_{j}$ is not from $A P$, Then round $D_{j}$ to nearest valid AP

Step5: best $2=\min \left(M C\left(D_{j}\right)\right)$, and worst $2=\max \left(M C\left(D_{j}\right)\right)$, for all $\mathrm{k}$

Step6: If best $2<$ best 1 , Then $\mathrm{C}_{\mathrm{j}}=\mathrm{D}_{\mathrm{j}}$, best $1=$ best 2 , worst $1=$ worst 2

Step7: Calculate $\operatorname{PD}\left(\mathrm{C}_{\mathrm{j}}\right)$

Step8: If $\mathrm{PD}\left(\mathrm{C}_{\mathrm{j}}\right)>$ fixed_Drop, Then Penalty will added to the total $\mathrm{MC}\left(\mathrm{C}_{\mathrm{j}}\right)$

Step9: Repeat steps 3-to-8 until JAYA loop ended

The output of second scenario illustrated in the Table 6, which it show different inputs, output, and executions, where the Figures 12, 13 shows one execution, which it gives the $M C$, and the $P D$ respectably, when the Jaya loop iterations $=100$, the candidate solution $(\mathrm{k})=10$, the $\min (M C)=31703$ at $\mathrm{j}=96$, and the fixed_Drop $=3800$. Table 7 shows specific values "derived from Table 6" of the $M C$, and how it decrease gradually, while the $P D$ were varied for each Jaya iteration. Figure 14 shows the effect of Jaya loop number on calculating the $M C$, and how the $M C$ improved while the Jaya loop were increase from (1001600) loop iterations, when using different values of fixed_Drop (3700-4000).

Table 6: Second Scenario Values

\begin{tabular}{|c|c|c|c|c|c|c|}
\hline & $\begin{array}{l}\text { JAYA } \\
\text { LOOP }\end{array}$ & $\begin{array}{c}\text { Fixed } \\
\text { drop }\end{array}$ & $\begin{array}{l}\min \\
\text { Cost }\end{array}$ & $\begin{array}{l}\text { The } \\
\text { Drop }\end{array}$ & $\begin{array}{l}\text { JAYA } \\
\text { Index }\end{array}$ & $\begin{array}{l}\text { Maintenance } \\
\text { times/Year }\end{array}$ \\
\hline 1 & \multirow{4}{*}{100} & 3700 & 63257 & 3826 & 77 & 124 \\
\hline 2 & & 3800 & 40847 & 3810 & 34 & 113 \\
\hline 3 & & 3900 & 34805 & 3678 & 40 & 77 \\
\hline 4 & & 4000 & 34306 & 3814 & 65 & 86 \\
\hline 5 & \multirow{4}{*}{200} & 3700 & 46482 & 3743 & 30 & 110 \\
\hline 6 & & 3800 & 35595 & 3775 & 363 & 93 \\
\hline 7 & & 3900 & 34371 & 3732 & 137 & 99 \\
\hline 8 & & 4000 & 33657 & 3718 & 194 & 92 \\
\hline 9 & \multirow{4}{*}{400} & 3700 & 45050 & 3747 & 135 & 87 \\
\hline 10 & & 3800 & 34969 & 3770 & 178 & 113 \\
\hline 11 & & 3900 & 34179 & 3766 & 241 & 88 \\
\hline 12 & & 4000 & 33131 & 3776 & 96 & 89 \\
\hline 13 & \multirow{4}{*}{800} & 3700 & 36736 & 3710 & 122 & 82 \\
\hline 14 & & 3800 & 34816 & 3745 & 172 & 89 \\
\hline 15 & & 3900 & 33356 & 3811 & 318 & 100 \\
\hline 16 & & 4000 & 32823 & 3695 & 287 & 84 \\
\hline 17 & \multirow{4}{*}{1600} & 3700 & 34607 & 3854 & 325 & 109 \\
\hline 18 & & 3800 & 33757 & 3662 & 40 & 71 \\
\hline 19 & & 3900 & 33317 & 3693 & 463 & 65 \\
\hline 20 & & 4000 & 32040 & 3585 & 1438 & 72 \\
\hline
\end{tabular}

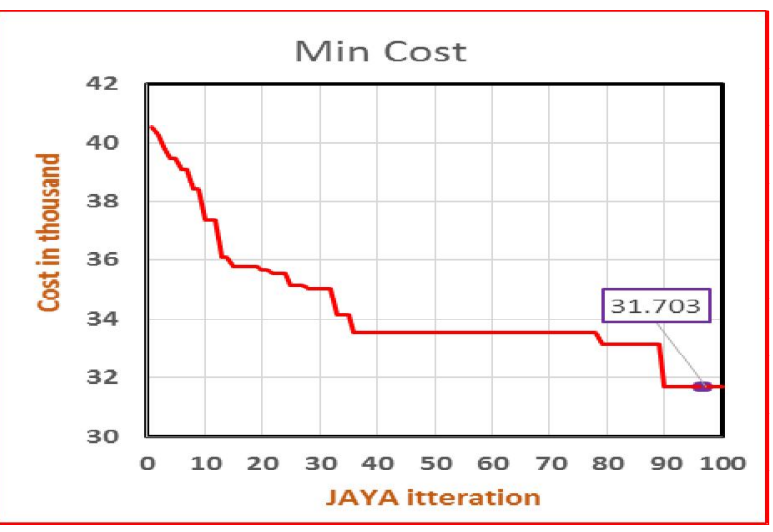

Figure 12: MC decresing with JAYA itteration

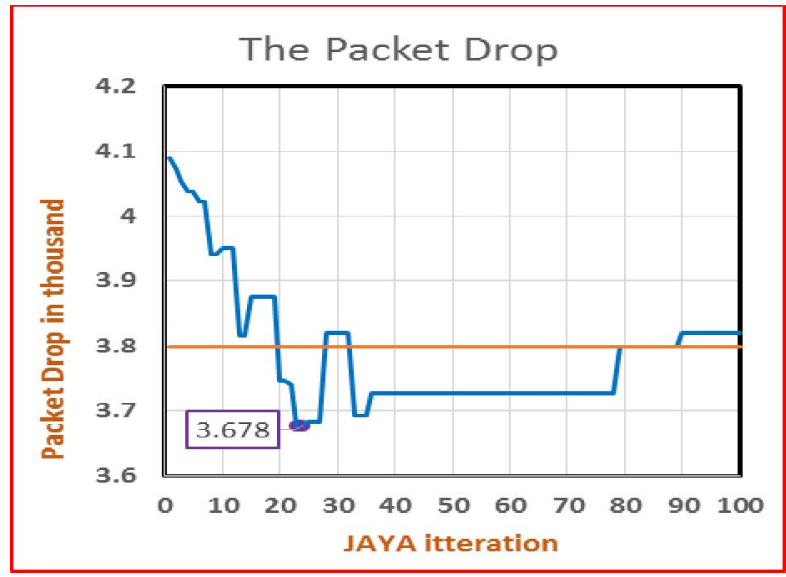

Figure 13: PD variation with JAYA itteration at fixed_Drop $=3800$ 
Table 7: MC Values

\begin{tabular}{|c|c|c|c|c|c|}
\hline fixed_Drop & JAYA=100 & 200 & 400 & 800 & 1600 \\
\hline 3700 & 63257 & 46482 & 45050 & 36736 & 34607 \\
\hline 3800 & 35712 & 35595 & 34969 & 34816 & 33757 \\
\hline 3900 & 34805 & 34371 & 34179 & 33356 & 33317 \\
\hline 4000 & 34306 & 33657 & 33131 & 32823 & 32040 \\
\hline
\end{tabular}

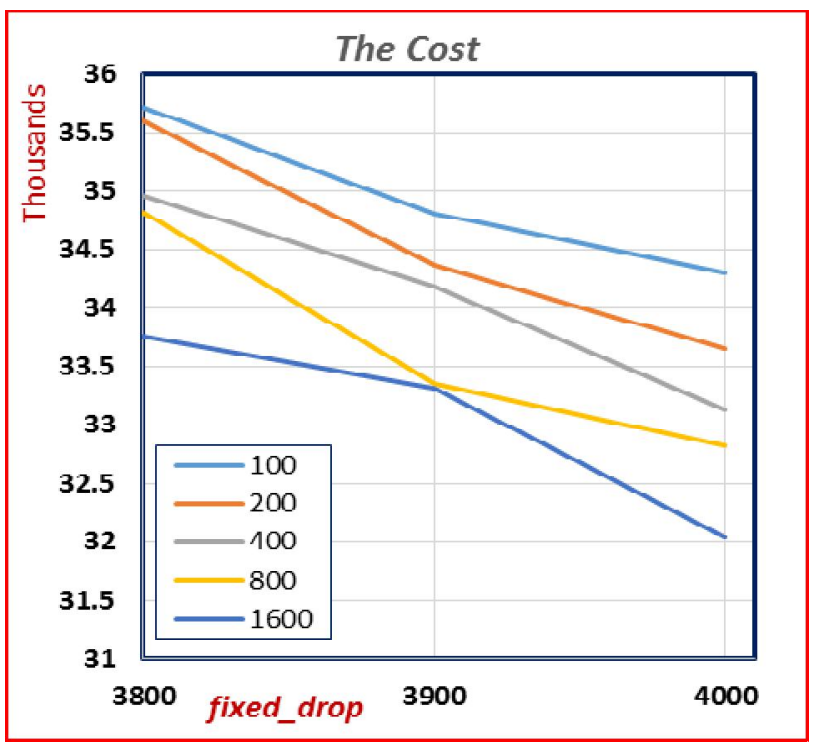

Figure 14: effect of five JAYA iteration on (MC) for different fixed_Drop

\section{CONCLUSION}

All components, whatever the makers were created them pure and ideal, the maintenance of devices is inevitable no matter how long time it takes. External factors (such as temperature, humidity, and dust ...etc.), and Internal factors (such as cheap and incompatible components, poor connections, electric failure, warm up, and also bad software used ...etc.) can effect on the regular operation and efficiency of any electronic components. Selecting the good maintenance strategy are very effective in extends the life of devices (network components), which depends on many factors (such as device lifetime, failure rate, allocated budget, device per packet, load per time, and packet loss allowed). The PM were proved one of the best maintenance strategies that can applied to the multi component system in many researches. This paper adopting part of Iraq network communications real map, where 14 gateway routers are present in this network, then by applying ON-OFF-ON plan randomly to these routers, and examine the network traffics for each case, then find the cost for all possibilities. Also present how maintenance cost MC can play very important role in reducing the packet drop, and increasing the overall system Availability. Exaggeration or careless in MC will produced high risk situation, and will effect on any system operations. This kind of problem, which the system Availability is very important, it is better to use The Metaheuristic JAYA algorithm due to its fast results producing and efficiency. The Packet drop and the cost are the most preliminary important to any networking company, and to make them at the minimum rate is the coordinate destination. There are two branches shown, the first is to make fixed_cost at rate then try to find the minimum packet drop, the second is to set fixed_drop at rate then find the minimum cost.

\section{REFERENCES}

[1] Ding, S.-H. and S. Kamaruddin Maintenance policy optimization-literature review and directions, The International Journal of Advanced Manufacturing Technology 76(5-8), 2015, pp.1263-1283. https://doi.org/10.1007/s00170-014-6341-2

[2] Hamdi, S. P. Hadiwardoyo, A. G. Correia and P. Pereira New optimization strategies of pavement maintenance: $A$ case study for national road network in Indonesia using integrated road management system, AIP Conference Proceedings, AIP Publishing, 2017. https://doi.org/10.1063/1.4985511

[3] Hemmati, N., M. Rahiminezhad Galankashi, D. M. Imani and $\mathrm{H}$. Farughi Maintenance policy selection: a fuzzyANP approach, Journal of Manufacturing Technology Management 29(7), 2018 pp.1253-1268. https://doi.org/10.1108/JMTM-06-2017-0109

[4] Javanmard, H. and A. a.-W. Koraeizadeh Optimizing the preventive maintenance scheduling by genetic algorithm based on cost and reliability in National Iranian Drilling Company, Journal of Industrial Engineering International 12(4), 2016, pp.509-516. https://doi.org/10.1007/s40092-016-0155-9

[5] Liang, Z., B. Liu, M. Xie and A. K. Parlikad Conditionbased Maintenance for Long-Life Assets with Exposure to Operational and Environmental Risks, International Journal of Production Economics, 2019. https://doi.org/10.1016/j.ijpe.2019.09.003

[6] Lin, B., J. Wu, R. Lin, J. Wang, H. Wang and X. Zhang Optimization of high-level preventive maintenance scheduling for high-speed trains, Reliability Engineering \& System Safety 183, 2019, pp.261-275.

https://doi.org/10.1016/j.ress.2018.11.028

[7] Pandey, H. M., M. Rajput and V. Mishra Performance comparison of pattern search, simulated annealing, genetic algorithm and jaya algorithm, Data Engineering and Intelligent Computing, Springer, 2018, pp.377-384. https://doi.org/10.1007/978-981-10-3223-3_36

[8] Rao, R. Jaya: A simple and new optimization algorithm for solving constrained and unconstrained optimization problems International Journal of Industrial Engineering Computations 7(1), 2016, pp.19-34. https://doi.org/10.5267/j.ijiec.2015.8.004

[9] Rao, R. V., V. J. Savsani and D. Vakharia Teachinglearning-based optimization: a novel method for constrained mechanical design optimization problems, Computer-Aided Design 43(3), 2011, pp.303-315. https://doi.org/10.1016/j.cad.2010.12.015

[10] Supriatna, A., M. L. Singgih, N. Kurniati and E. Widodo PREVENTIVE MAINTENANCE STRATEGIES: LITERATURE REVIEW AND DIRECTIONS, International Conference on Operations and Supply Chain Management, 2016, pp.127-139.

[11] Tsunoda, M., A. Monden, K. Matsumoto, S. Ohiwa and T. Oshino Benchmarking software maintenance based on working time, 3rd International Conference on Applied Computing and Information Technology/2nd International Conference on Computational Science and Intelligence, IEEE, 2015. https://doi.org/10.1109/ACIT-CSI.2015.13

[12] Vilarinho, S., I. Lopes and J. A. Oliveira Preventive maintenance decisions through maintenance optimization models: a case study, Procedia Manufacturing 11, 2017, pp.1170-1177. https://doi.org/10.1016/j.promfg.2017.07.241 
[13] Zhong, S., A. A. Pantelous, M. Goh and J. Zhou A reliability-and-cost-based fuzzy approach to optimize preventive maintenance scheduling for offshore wind farms." Mechanical Systems and Signal Processing 124, 2019, pp.643-663

https://doi.org/10.1016/j.ymssp.2019.02.012

[14] Amin Salih Mohammed and Hiwa Abdulkarim Mawlood QoS Performance Evaluation in 4G and 5G Comparison, International Journal of Advanced Trends in Computer Science and Engineering, Volume 8, No 1.2, 2019, pp. 14-19.

[15] Saleem Basha, Gazala yusufi, Rajbunisa, Abbas and Saravana Balaji B, BIO-INSPIRED DEPENDABILITY ANALYSIS OF SECURITY IN SOFTWARE DEVELOPMENT LIFE CYCLE PROCESS, International Journal of Advanced Trends in Computer Science and Engineering, Volume 8, No 1.2, 2019, pp. 116121. 